\title{
Completeness and timeliness of tuberculosis notification in Taiwan
}

Hsiu-Yun Lo ${ }^{1,2}$, Shiang-Lin Yang ${ }^{2}$, Pesus Chou', Jen-Hsiang Chuang ${ }^{1,2}$ and Chen-Yuan Chiang ${ }^{3,4,5^{*}}$

\begin{abstract}
Tuberculosis (TB) is a notifiable disease by the Communicable Disease Control Law in Taiwan. Several measures have been undertaken to improve reporting of TB but the completeness and timeliness of TB notification in Taiwan has not yet been systemically evaluated.

Methods: To assess completeness and timeliness of TB notification, potential TB cases diagnosed by health care facilities in the year 2005-2007 were identified using the reimbursement database of national health insurance $(\mathrm{NHI})$, which has $99 \%$ population coverage in Taiwan. Potential TB patients required notification were defined as those who have TB-related ICD-9 codes (010-018) in the NHI reimbursement database in 2005-2007, who were not diagnosed with TB in previous year, and who have been prescribed with 2 or more types of anti-TB drugs. Each potential TB case was matched to the national TB registry maintained at Taiwan Centers for Disease Control (CDC) by using national identity number or, if non-citizen, passport number to determine whether the patients had been notified to local public health authorities and Taiwan CDC. The difference in the number of days between date of anti-tuberculosis treatment and date of notification was calculated to determine the timeliness of TB reporting.
\end{abstract}

Results: Of the 57,405 TB patients who were prescribed with 2 or more anti-tuberculosis drugs, 55,291 (96.3\%) were notified to National TB Registry and 2,114 (3.7\%) were not. Of the 55,291 notified cases, 45,250 (81.8\%) were notified within 7 days of anti-tuberculosis treatment (timely reporting) and 10,041(18.2\%) after 7 days (delayed reporting). Factors significantly associated with failure of notification are younger age, previously notified cases, foreigner, those who visited clinics and those who visited health care facilities only once or twice in 6 months.

Conclusion: A small proportion of TB cases were not notified and a substantial proportion of notified TB cases had delayed reporting, findings with implication for strengthening surveillance of tuberculosis in Taiwan. Countries where the completeness and timeliness of TB notification has not yet been evaluated should take similar action to strengthen surveillance of TB.

Keywords: Completeness, Notification, Reporting, Tuberculosis

\section{Background}

Tuberculosis (TB) remains a major public health problem in Taiwan. In 2009, a total of 13827 TB cases (13336 new and 491 relapse) were notified to Taiwan Centers for Disease Control (CDC); the notification rate of TB was 59.9 per 100000 population and TB mortality was 3.2 per 100000 population [1]. Complete and timely notification of TB to public health authorities is one of the essential components of TB control [2]. In Taiwan, notification of TB initiates assessment of TB cases by

\footnotetext{
* Correspondence: cychiang@theunion.org

${ }^{3}$ Department of Lung Health and NCDs, International Union Against

Tuberculosis and Lung Disease, boulevard Saint-Michel, 75006 Paris, France

Full list of author information is available at the end of the article
}

public health nurses, assignment of directly observed therapy (DOT) observers, and contact tracing. Proper notification of TB provides surveillance data to keep track of the epidemic of tuberculosis.

TB is a notifiable disease by the Communicable Disease Control Law in Taiwan. Several measures have been undertaken to improve notification of TB. The Bureau of National Health Insurance (NHI) introduced the no-notification-no- reimbursement (NNNR) policy and the notification-fee (NF) policy in 1997, resulting in a prompt increase in TB notification and the number of notified TB cases reached a historical peak in 1997 [3]. Further, Taiwan CDC periodically cross matched vital 
registration and National TB registry to identify failure of notification of cases who died of TB.

The completeness and timeliness of TB notification in Taiwan has not yet been systemically evaluated. The Bureau of NHI maintains a reimbursement database containing health care services provided by health care facilities who have signed contracts with the Bureau of NHI. We use the NHI reimbursement database to assess completeness and timeliness of TB notification in Taiwan. We report results of this study.

\section{Materials}

We identify potential TB cases diagnosed by health care facilities in 2005-2007 using prescription records of the NHI reimbursement database. Each potential TB case was matched to the national $\mathrm{TB}$ registry maintained at Taiwan CDC by using national identity number or, if non-citizen, passport number to determine whether the patient had been notified to local public health authorities and Taiwan CDC. The difference in the number of days between date of anti-TB treatment and date of notification was calculated to determine the timeliness of $\mathrm{TB}$ reporting.

\section{National health insurance database}

The NHI Program was run by the government under the principle of mandatory and universal enrollment. The proportion of the population insured under the NHI Program was initially 92\% when the NHI program was launched in 1995, and $99 \%$ of the populations was covered by NHI in the end of 2008 [4,5]. With the implementation of the NHI program, most hospitals and clinics (more than 90\%) have signed contracts with the Bureau of NHI, and fee-for-service is reimbursed by the Bureau of NHI on a monthly schedule. The NHI reimbursement database is case-based, including individual information of national identity number, sex, birthday, dates of outpatient visit and hospitalization, examinations, diagnosis using the International Classification of Disease, ninth revision (ICD-9) coding system and treatment.

\section{TB services in Taiwan}

TB service was mainly provided through a vertical programme in the past. Re-structuring of the TB control programme took place in 2001. Thereafter, diagnosis and treatment of TB have been provided through general health care system. Currently, TB patients can receive anti-TB treatment in any clinic or hospital, through the coverage of the NHI Program. However, there is no TB case register at facility level. Management of TB cases (DOT, contact tracing) are the responsibility of the public sector. The link between general health care facilities and the public sector for the management of $\mathrm{TB}$ cases is established through $\mathrm{TB}$ notification.

\section{TB notification and the computerized TB registration system}

Taiwan has established a TB registry for decades. Taiwanese regulations stipulate that all suspected and confirmed TB cases should be reported to the local Department of Health in each city/county within 7 days. Upon receiving notification, a public health nurse (PHN) in each township/village health station is responsible for patients visit (within seven days of notification), completion of a standard registration form, and supervision of DOT observers in performing DOT. A computerized National TB Register with a registration network was established in 1994 [3]. With the establishment of the computerized system, the PHN in each township/village health station is responsible for entering reports of suspected and confirmed TB cases (reported cases) into the National TB Register via the registration network. A web-based TB notification system was launched in 2002 . The proportion of TB notified through the web-based notification system was $78.8 \%$ in $2005,88.5 \%$ in 2006 , and $94 \%$ in 2007 . The TB registry is also a case-based system including patients' national identity number (or, if non-citizen, passport number), birthday, sex, bacteriological examination (smear for acid-fast stain and culture for M. tuberculosis), site of disease (pulmonary TB, extrapulmonary TB), date of initiation of anti-TB treatment, treatment regimen, and outcome of treatment.

\section{Definition of TB case}

For the purpose of this study, TB patients required notification are those who have TB-related ICD-9 codes (010-018) in the NHI reimbursement database in 20052007, who were not diagnosed with TB in previous year, and who have been prescribed with 2 or more types of anti-TB drugs, including Isoniazid (H), Ethambutol (E), Rifampin (R), Pyrazinamide (Z), Prothionamide (PAS), Aminogylcoside (streptomycin, amikacin, and kanamycin) and Quinolone (ciprofloxacin, levofloxacin, ofloxacin and moxifloxacin), within 6 months.

Procedure of investigation

1. We identified patients who had TB-related ICD-9 codes in the NHI reimbursement database in 2005-2007.

2. We excluded those who already had TB-related ICD-9 codes in previous year.

3. We checked whether patients who were newly assigned with TB-related ICD-9 codes have been prescribed with anti-TB drugs.

4. Those who have been prescribed with 2 or more types of anti-TB drugs were matched to the national TB registry by using national identity number or, if noncitizen, passport number to determine whether they had 
been notified by 30 June 2008. Cases who could not be found at the national TB registry were classified as not notified. For those who have been notified previously and who have retreatment of TB in 2005-2007, we checked whether they were re-notified as retreatment cases. If not, they were also classified as not notified.

5. We investigated factors associated with failure of notification.

6. We calculated the difference in the number of days between date of initiation of anti-TB treatment and date of notification to assess timeliness of notification. Cases notified within 7 days of anti-TB treatment are classified as having timely reporting and after 7 days delayed reporting.

7. We investigated factors associated with delayed reporting.

8. We checked the completeness of data entry of critical fields of notification form, including name, sex, birthday, address, reporting health care facilities, medical chart number, name of reporting doctor, date of diagnosis, site of disease (pulmonary and/or extrapulmonary) and smear examinations.

\section{Statistics analysis}

SAS 9.2 (SAS Institute Inc., Cary, NC, USA) and Microsoft Excel 2007 were used for data management and analysis. We assessed whether, age group, sex, type of case, nationality, type of health care facilities, and number of visit to health care facilities in 6 months were associated with failure of notification of TB and delayed reporting in univariate analysis by chi square test. Variables that were significantly associated with failure of notification or delayed reporting in a univariate analysis $(P<0.05)$ were selected for multivariable logistic regression analyses by stepwise approach and likelihood ratio test was used to determine the final fitted model. Stratified analysis was performed to assess interaction in under-notification between nationality, type of cases and number of health care facilities visits in 6 months, and in delayed reporting between age groups, type of cases and type of health care facilities. $P$ value $<0.05$ was regarded as statistically significant.

This study was approved by the Institute Review Board of Taiwan CDC.

\section{Results}

There were 209,095 patients who had TB-related ICD-9 codes in the year 2005-2007 in the NHI reimbursement database. (Figure 1) Of the 209,095 patients, 64,377 (30.8\%) had been assigned with TB-related ICD-9 codes in previous year and 144,718 (69.2\%) were newly assigned with TB-related ICD-9 codes in the year 20052007. Of the 144,718 patients, 84,361 (58.3\%) were not prescribed with any anti-TB drugs within 6 months after being assigned with TB-related ICD-9 codes, 2,952 (2.1\%) were prescribed with one anti-TB drug, 57,405 (39.7\%) were prescribed with 2 or more type of anti-TB drugs. Of the 57,405 patients, 55,291 (96.3\%) were notified and 2,114 (3.7\%) were not. Of the 57,405 patients, $52,763(91.9 \%)$ were new TB cases and 4,642 (8.1\%) were retreatment cases who had been notified previously. Of the 52,763 new TB cases, 1,270 (2.4\%) were not notified, and of the 4,642 retreatment cases, 844 $(18.2 \%)$ were not notified. $(p<0.001)$

Table 1 shows factors associated with failure of notification of TB. The proportion of un-notified cases was higher among patients aged $25-44$ years $(5.6 \%)(p<$ $0.001)$, retreatment cases $(18.2 \%)(p<0.001)$, foreigners $(22.8 \%)(p<0.001)$, those who visited clinics $(5.9 \%)(p<$ $0.001)$, and those who visited health care facilities only once $(14.1 \%)$, or twice $(8.2 \%)(p<0.001)$, as compared with other groups. In multivariate analysis, factors significantly associated with failure of notification of TB were age groups $(\leqq 24$ years, adjOR $1.8,95 \%$ CI 1.5-2.3; 25-44 years, adjOR 2.1, 95\% CI 1.8-2.4; 45-64 years, adjOR 1.5, 95\% CI 1.3-1.7; as compared with aged 65 years or more), retreatment cases (adjOR 11.5, 95\% CI 10.4-12.8), foreigner (adjOR 6.8, 95\% CI 5.6-8.1), type of health care facilities (clinic, adjOR 2.3, 95\% CI 1.9-2.7; district hospital, adjOR 1.7, 95\% CI 1.5-1.9; regional hospital, adjOR 1.2, 95\% CI 1.1-1.3. as compared with medical centers) and number of visits to health care facilities in 6 months (once, adjOR 11.4, 95\% CI 10.2-12.7; twice, adjOR 5.3, 95\% CI 4.6-6.2, as compared with 3 times or more).

Table 2 shows TB notification among citizen and foreigner, stratified by type of case and number of health facilities visits. The proportion of previously notified cases among citizens was higher than that among foreigners $(8.3 \%$ vs. $0.5 \%)$. The interaction between nationality and type of case was statistically significant $(p=$ 0.04 ). The association between type of case and undernotification was statistically significant among citizens but not among foreigners. Under-notification of new TB cases was substantial among foreigners but not among citizens $(22.9 \%$ vs. $1.9 \%)$. The proportion of patients who had visited health facilities for only once in 6 months was higher among foreigners than that among citizens $(31.1 \%$ vs. $13.3 \%)$. The interaction between nationality and number of visits to health care facility in 6 months was also statistically significant (nationality * once: $p<0.01$; nationality * twice: $p=0.63$ ). Undernotification of those who visited health facilities only once $(43.7 \%)$ or twice $(37.0 \%)$ was particularly high among foreigners.

Of the 55,291 notified cases, 45,250 (81.8\%) were notified within 7 days of anti-TB treatment; 10,041(18.2\%) were notified after 7 days ( $14.5 \%$ in $8-30$ days, $2.9 \%$ in 


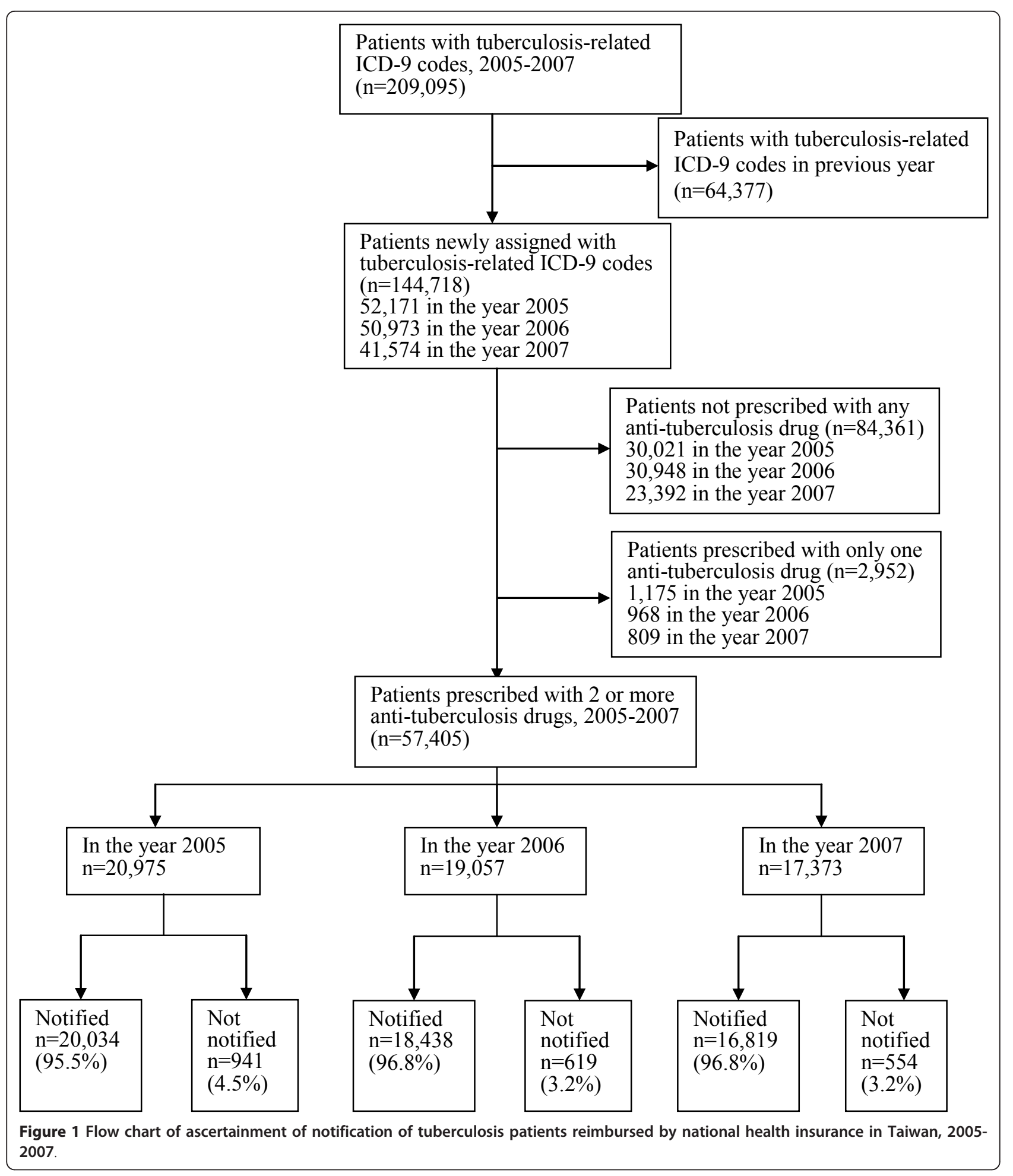

31-90 days and $0.7 \%$ after 90 days) and were considered as having delayed reporting. Higher proportions of new cases were notified within 7 days of anti-TB treatment (81.3\% in $2005,82.8 \%$ in 2006 and $84.1 \%$ in 2007 ) as compared with retreatment cases $(73.5 \%$ in $2005,72.8 \%$ in $2006,65.9 \%$ in 2007$)(p<0.001)$. (Table 3$)$. The proportion of retreatment cases with timely reporting was $73.5 \%$ in 2005 , which decreased to $65.9 \%$ in 2007 .

Table 4 shows factors associated with delayed reporting. In multivariate analysis, factors significantly 
Table 1 Factors associated with failure of notification of tuberculosis in Taiwan, 2005-2007

\begin{tabular}{|c|c|c|c|c|c|c|c|c|}
\hline & \multicolumn{2}{|c|}{$\begin{array}{l}\text { Total } \\
\mathrm{n}=5,7405 \\
\mathrm{n} \text { (column } \%)\end{array}$} & \multicolumn{2}{|c|}{$\begin{array}{l}\text { Notified } \\
n=55,291 \\
n \text { (row\%) }\end{array}$} & \multicolumn{2}{|c|}{$\begin{array}{l}\text { Not notified } \\
\mathrm{n}=2,114 \\
\mathrm{n}(\text { (row\%) }\end{array}$} & \multicolumn{2}{|c|}{$\begin{array}{l}\text { Multivariate analysis } \\
\text { adjOR }(95 \% \mathrm{Cl})\end{array}$} \\
\hline \multicolumn{9}{|l|}{ Age group $(y / r)^{*}$} \\
\hline $0-24$ & 3,584 & $(6.2)$ & 3,459 & (96.5) & 125 & (3.5) & 1.8 & $(1.5-2.3)$ \\
\hline $25-44$ & 9,996 & $(17.4)$ & 9,441 & (94.4) & 555 & (5.6) & 2.1 & $(1.8-2.4)$ \\
\hline $45-64$ & 15,072 & $(26.3)$ & 14,554 & (96.6) & 518 & (3.4) & 1.5 & $(1.3-1.7)$ \\
\hline$\geq 65$ & 28,753 & $(50.1)$ & 27,837 & (96.8) & 916 & $(3.2)$ & 1.0 & \\
\hline \multicolumn{9}{|l|}{ Sex* } \\
\hline male & 38,534 & $(67.1)$ & 37,180 & $(96.5)$ & 1,354 & $(3.5)$ & & \\
\hline female & 18,869 & (32.9) & 18,111 & (96.0) & 758 & $(4.0)$ & & \\
\hline \multicolumn{9}{|l|}{ Type of case* } \\
\hline new cases & 52,763 & (91.9) & 51,493 & (97.6) & 1,270 & $(2.4)$ & 1.0 & \\
\hline previously notified cases & 4,642 & $(8.1)$ & 3,798 & $(81.8)$ & 844 & $(18.2)$ & 11.5 & $(10.4-12.8)$ \\
\hline \multicolumn{9}{|l|}{$\overline{\text { Nationality* }}$} \\
\hline citizen & 56,024 & (97.6) & 54,225 & (96.8) & 1,799 & (3.2) & 1.0 & \\
\hline foreigner & 1,381 & $(2.4)$ & 1,066 & $(77.2)$ & 315 & $(22.8)$ & 6.8 & $(5.6-8.1)$ \\
\hline \multicolumn{9}{|l|}{ Type of health care facilities* } \\
\hline medical center & 19,770 & (34.4) & 19,269 & $(97.5)$ & 501 & $(2.5)$ & 1.0 & \\
\hline regional hospital & 22,664 & $(39.5)$ & 21,854 & (96.4) & 810 & (3.6) & 1.2 & $(1.1-1.3)$ \\
\hline district hospital & 11,273 & $(19.6)$ & 10,689 & $(94.8)$ & 584 & $(5.2)$ & 1.7 & $(1.5-1.9)$ \\
\hline clinic & 3,698 & $(6.4)$ & 3,479 & $(94.1)$ & 219 & $(5.9)$ & 2.3 & $(1.9-2.7)$ \\
\hline \multicolumn{9}{|c|}{ Number of visits to health care facilities in 6 months* } \\
\hline once & 7,876 & $(13.7)$ & 6,763 & $(85.9)$ & 1,113 & $(14.1)$ & 11.4 & $(10.2-12.7)$ \\
\hline twice & 3,722 & $(6.5)$ & 3,417 & (91.8) & 305 & $(8.2)$ & 5.3 & $(4.6-6.2)$ \\
\hline 3 or more & 45,807 & (79.8) & 45,111 & (98.5) & 696 & $(1.5)$ & 1.0 & \\
\hline
\end{tabular}

* Statistically significant in univariate analysis $(P<0.05)$.

Table 2 Tuberculosis notification among citizen and foreigner, stratified by type of case and number of health facilities visits

\begin{tabular}{|c|c|c|c|c|c|c|c|c|c|}
\hline & \multicolumn{2}{|c|}{$\begin{array}{l}\text { Total } \\
\text { n (column \%) }\end{array}$} & \multicolumn{2}{|c|}{$\begin{array}{l}\text { Not notified } \\
\text { n (row\%) }\end{array}$} & \multicolumn{2}{|c|}{$\begin{array}{l}\text { Notified } \\
\text { n (row \%) }\end{array}$} & adjOR* & $(95 \% \mathrm{Cl})$ & $p$ \\
\hline previously notified cases & 4,635 & $(8.3)$ & 843 & $(18.2)$ & 3,792 & $(81.8)$ & 11.7 & $(10.5-13.1)$ & $<0.001$ \\
\hline new cases & 51,389 & $(91.7)$ & 956 & $(1.9)$ & 50,433 & $(98.1)$ & & & \\
\hline \multicolumn{10}{|l|}{ Foreigner } \\
\hline previously notified cases & 7 & $(0.5)$ & 1 & $(14.3)$ & 6 & $(85.7)$ & 1.9 & $(0.1-10.7)$ & 0.88 \\
\hline new cases & 1,374 & $(99.5)$ & 314 & $(22.9)$ & 1,060 & $(77.1)$ & & & \\
\hline \multicolumn{10}{|l|}{ Citizen } \\
\hline health facilities visits only once & 7,446 & $(13.3)$ & 925 & $(12.4)$ & 6,521 & $(87.6)$ & 12.0 & $(10.7-13.5)$ & $<0.001$ \\
\hline health facilities visits twice & 3,576 & $(19.1)$ & 251 & $(7.0)$ & 3,325 & $(93.0)$ & 5.2 & $(4.4-6.1)$ & $<0.001$ \\
\hline health facilities visits $\geq 3$ times & 45,002 & $(80.3)$ & 623 & $(1.4)$ & 44,379 & $(98.6)$ & ref. & & \\
\hline \multicolumn{10}{|l|}{ Foreigner } \\
\hline health facilities visits once & 430 & $(31.1)$ & 188 & $(43.7)$ & 242 & $(56.3)$ & 7.6 & $(5.6-10.4)$ & $<0.001$ \\
\hline health facilities visits twice & 146 & $(10.6)$ & 54 & $(37.0)$ & 92 & $(63.0)$ & 5.8 & $(3.8-8.8)$ & $<0.001$ \\
\hline health facilities visits $\geq 3$ times & 805 & $(58.3)$ & 73 & $(9.1)$ & 732 & $(90.9)$ & ref. & & \\
\hline
\end{tabular}

${ }^{*}$ Adjusted by age, type of health care facilities and type of cases or number of health facilities visits 
Table 3 Timeliness of notification of tuberculosis in Taiwan, 2005-2007

\begin{tabular}{|c|c|c|c|c|c|c|c|c|c|c|c|c|c|c|}
\hline & \multicolumn{2}{|c|}{ Number of patients (\%) } & \multicolumn{6}{|c|}{ New cases } & \multicolumn{6}{|c|}{ Previously notified cases } \\
\hline & & & \multicolumn{2}{|l|}{2005} & \multicolumn{2}{|l|}{2006} & \multicolumn{2}{|l|}{2007} & \multicolumn{2}{|l|}{2005} & \multicolumn{2}{|l|}{2006} & \multicolumn{2}{|l|}{2007} \\
\hline & & & $\mathbf{n}$ & (\%) & $\mathrm{n}$ & $(\%)$ & $\mathbf{n}$ & (\%) & $\mathrm{n}$ & $(\%)$ & $\mathbf{n}$ & (\%) & $\mathrm{n}$ & $(\%)$ \\
\hline Total & 55,291 & 100.0 & 18,662 & 100.0 & 17,135 & 100.0 & 15,696 & 100.0 & 1,372 & 100.0 & 1,303 & 100.0 & 1,123 & 100.0 \\
\hline 0-7 days & 45,250 & 81.8 & 15,176 & 81.3 & 14,181 & 82.8 & 13,196 & 84.1 & 1,008 & 73.5 & 949 & 72.8 & 740 & 65.9 \\
\hline 8-30 days & 8,006 & 14.5 & 2,771 & 14.8 & 2,362 & 13.8 & 2,040 & 13.0 & 280 & 20.4 & 273 & 21.0 & 280 & 24.9 \\
\hline $31-90$ days & 1,630 & 2.9 & 555 & 3.0 & 477 & 2.8 & 399 & 2.5 & 51 & 3.7 & 62 & 4.8 & 86 & 7.7 \\
\hline$\geqq 91$ days & 405 & 0.7 & 160 & 0.9 & 115 & 0.7 & 61 & 0.4 & 33 & 2.4 & 19 & 1.5 & 17 & 1.5 \\
\hline
\end{tabular}

associated with delayed reporting were the following: patients aged 45-64 years (adjOR 1.2, 95\% CI 1.1-1.3), $\geqq 65$ years (adjOR 2.0, 95\% CI 1.9-2.1), as compared with patients aged $\leqq 24$ years; previously treated cases (adjOR 1.9, 95\% CI 1.8-2.1) as compared with new cases; citizens (adjOR 1.8, 95\% CI 1.4-2.2) as compared with foreigners; patients treated in medical center (adjOR 3.8, 95\% CI 3.3-4.4), regional hospital (adjOR 2.9, 95\% CI 2.5-3.4) and district hospital (adjOR 2.5, 95\% CI 2.2-2.9) as compared with clinic patients; those who visited health care facilities once
(adjOR 2.9, 95\% CI 2.7-3.0), or twice (adjOR 1.6, 95\% CI 1.5-1.7) in 6 months as compared with 3 times or more. The interaction between age group and type of health facility, and between type of case and type of health facility was statistically significant. Stratifying delayed notification among age groups and type of cases by types of health facilities demonstrated that the proportion with delayed notification was consistently highest in medically centers, followed by regional hospital, district hospital and clinics in all strata (data not shown).

Table 4 Factors associated with delayed reporting of tuberculosis in Taiwan, 2005-2007

\begin{tabular}{|c|c|c|c|c|c|c|c|c|}
\hline & \multirow{2}{*}{\multicolumn{2}{|c|}{$\begin{array}{l}\text { Total } \\
n=55,291 \\
n \text { (column\%) }\end{array}$}} & \multirow{2}{*}{\multicolumn{2}{|c|}{$\begin{array}{l}\text { Timely } \\
\mathrm{n}=45,250 \\
\mathrm{n} \text { (row\%) }\end{array}$}} & \multirow{2}{*}{\multicolumn{2}{|c|}{$\begin{array}{l}\begin{array}{l}\text { Delayed } \\
n=10,041\end{array} \\
n \text { (row\%) }\end{array}$}} & \multicolumn{2}{|c|}{ Multivariate analysis } \\
\hline & & & & & & & adjOR & $(95 \% \mathrm{Cl})$ \\
\hline \multicolumn{9}{|l|}{ Age group* $(y / r)$} \\
\hline $0-24$ & 3,459 & $(6.3)$ & 3,131 & $(90.5)$ & 328 & $(9.5)$ & 1.0 & \\
\hline $25-44$ & 9,441 & $(17.1)$ & 8,381 & $(88.8)$ & 1,060 & $(11.2)$ & 0.9 & $(0.8-1.0)$ \\
\hline $45-64$ & 14,554 & $(26.3)$ & 12,412 & (85.3) & 2,142 & $(14.7)$ & 1.2 & $(1.1-1.3)$ \\
\hline$\geq 65$ & 27,837 & $(50.3)$ & 21,326 & $(76.6)$ & 6,511 & $(23.4)$ & 2.0 & $(1.9-2.1)$ \\
\hline \multicolumn{9}{|l|}{$\operatorname{Sex}^{*}$} \\
\hline female & 18,111 & $(32.8)$ & 14,957 & $(82.6)$ & 3,154 & $(17.4)$ & & \\
\hline male & 37,180 & $(67.2)$ & 30,293 & $(81.5)$ & 6,887 & $(18.5)$ & & \\
\hline \multicolumn{9}{|l|}{ Type of case* } \\
\hline new cases & 51,493 & $(93.1)$ & 42,553 & $(82.6)$ & 8,940 & $(17.4)$ & 1.0 & \\
\hline previously notified cases & 3,798 & $(6.9)$ & 2,697 & $(71.0)$ & 1,101 & $(29.0)$ & 1.9 & $(1.8-2.1)$ \\
\hline \multicolumn{9}{|l|}{ Nationality* } \\
\hline foreigner & 1,066 & $(1.9)$ & 978 & $(91.7)$ & 88 & (8.3) & 1.0 & \\
\hline citizen & 54,225 & $(98.1)$ & 44,272 & $(81.6)$ & 9,953 & $(18.4)$ & 1.8 & $(1.4-2.2)$ \\
\hline \multicolumn{9}{|l|}{ Type of health care facilities* } \\
\hline medical center & 19,269 & $(34.9)$ & 15,150 & $(78.6)$ & 4,119 & $(21.4)$ & 3.8 & $(3.3-4.4)$ \\
\hline regional hospital & 21,854 & $(39.5)$ & 17,909 & $(81.9)$ & 3,945 & $(18.1)$ & 2.9 & $(2.5-3.4)$ \\
\hline district hospital & 10,689 & $(19.3)$ & 8,934 & $(83.6)$ & 1,755 & $(16.4)$ & 2.5 & $(2.2-2.9)$ \\
\hline clinic & 3,479 & $(6.3)$ & 3,257 & (93.6) & 222 & $(6.4)$ & 1.0 & \\
\hline \multicolumn{9}{|c|}{ Number of visits to health care facilities in 6 months* } \\
\hline 1 & 6,763 & $(12.2)$ & 4,303 & (63.6) & 2,460 & $(36.4)$ & 2.9 & $(2.7-3.0)$ \\
\hline 2 & 3,417 & $(6.2)$ & 2,613 & $(76.5)$ & 804 & $(23.5)$ & 1.6 & $(1.5-1.7)$ \\
\hline$\geq 3$ & 45,111 & (81.6) & 38,334 & (85.0) & 6,777 & (15.0) & 1.0 & \\
\hline
\end{tabular}

* Statistically significant in univariate analysis $(P<0.05)$. 
Completion of data entry of critical fields of notification form were $100 \%$ for patients' name, sex, birthday, address, reporting health care facilities, medical chart number, name of reporting doctors, and date of diagnosis. Of the 55291 patients, $21(0.04 \%)$ had no information on site of disease. Of the 51992 pulmonary TB cases, $1386(2.7 \%)$ had no information on smear examinations.

\section{Discussion}

Accurate, complete and timely reporting of notifiable diseases provide surveillance data to estimate disease burden, detect sporadic outbreaks and monitor epidemiological trends. Active surveillance may strengthen the completeness and accuracy of passive surveillance data [6-8]. As the majority of Taiwan citizens have been participated in the NHI program, the NHI reimbursement database offers a unique opportunity to conduct active surveillance to investigate completeness and timeliness of TB notification in Taiwan. We used prescription of 2 or more anti-TB drugs to identify potential TB cases diagnosed by clinicians. This approach has been applied in other settings previously $[9,10]$. Patients who were prescribed with only one anti-TB drugs was not included in this study because the majority of these cases were prescribed with either isoniazid, an aminoglycoside or a fluoroquinolone alone and may not fit the case definition of active TB.

Completeness of reporting of notifiable infectious diseases has been reported previously. Doyle and colleagues investigated reporting of notifiable infectious diseases in the US and found that reporting completeness varied from $9 \%$ to $99 \%$ and was most strongly associated with the disease being reported [6]. Studies in the US using various combinations of data of laboratory, clinic, pharmacy, and hospital discharge records reported that reporting completeness for $\mathrm{TB}$ ranged from $65 \%$ to 99.5\% [8,10-13]. In United Kingdom, under-notification ranged from $7 \%$ to $27 \%[14,15]$. Backer et al. listed several reasons related to under reporting, including insufficient consultation hours, patient privacy, not knowing notification is required, reporting severe disease only, lack of laboratory confirmation, considering other health care worker will report, and not knowing report procedure [16].

Under-reporting of $\mathrm{TB}$ has been an issue in private sectors as well as public sectors not involved in national TB programme. Chiang et al. did a survey on TB services in big cities and reported substantial under-reporting in Bangkok, Dhaka, Jakarta, Karachi, Kathmandu, and Manila [17]. Masjedi et al. investigated notification of 646 smear positive TB patients detected in the private laboratories in Tehran and reported that $87.3 \%$ of these patients could not be traced [18]. Improved TB notification by public-public and public-private mix approach has been reported from studies in China [19], India [20], Indonesia [21], Kenya [22], Myanmar [23], Nepal [24], and Vietnam [19]

Our study revealed that under-notification of TB in Taiwan was not high and decreased from 4.5\% in 2005 to $3.2 \%$ in 2007 , probably reflecting the impact of activities in strengthening surveillance of TB in Taiwan. However, timeliness of $\mathrm{TB}$ reporting was a concern because $18.8 \%$ of cases had delayed reporting. Younger age groups, especially those aged 25-44 years old, were more likely to be under reported. We speculated that TB may affect their job opportunity resulting in under reporting to keep TB confidential, which highlighted the importance of health education on TB in Taiwan. While delayed reporting decreased from $19.2 \%$ in 2005 to $17.1 \%$ in 2007 in the study population, delayed reporting occurred more frequently among the elderly. We speculated that this was due to difficulty in the diagnosis of TB among the elderly whose clinical manifestations were complicated by co-morbidity. Previously treated cases were substantially under notified (18.2\%) and if notified, had delayed reporting (29.0\%), probably because the notification system was not clear in guiding re-notification of patients who had already been registered previously. However, under-notification among foreigners was substantial not only in previously notified TB cases but also new TB cases. Further, a high proportion of foreigners have visited health care facilities for only once or twice in 6 months. We speculated that these were because they left Taiwan after the diagnosis of TB. Patients who visited health care facilities once or twice in 6 months were associated with under notification and delayed reporting. We did not know what happen to them (including foreigners). They might be died, or defaulted and remained source of transmission in the community.

Timeliness of notification of infectious disease and TB has been reported in other settings. Yoo et al. reported that time from disease onset to diagnosis contributed most to the delay in reporting [25]. Ward et al. reported that reporting of infectious diseases through an internet based reporting system had less reporting delay as compared with reporting through the conventional paperbased system [26]. Curtis et al. reported that the proportion of cases with delayed reporting ( $>7$ days) varied from $5 \%$ to $53 \%$ between sites and that factors associated with delayed reporting included infectiousness, type of provider, diagnosing provider, and reporting source [8]. Our study revealed that medical centers had the lowest proportion of patients under-notified but the highest proportion of patients with delayed reporting. We speculated that medical centers were more likely to have a system in place to ensure completeness of $\mathrm{TB}$ 
notification. Those who were not reported were captured at a later point in time and notified, and were classified as delayed reporting.

Completion of data entry of critical fields of notification form were $100 \%$ for patients' name, sex, birthday, address, reporting health care facilities, medical chart number, name of reporting doctors, and date of diagnosis, partly because these fields must be entered in the web-based notification system and because the majority were notified through the web-based system. Sputum smear examinations have been emphasized but were not set as "must enter" reporting fields in the web-based notification system to facilitate timely reporting. Clearly, it is essential to strengthen the information system to obtain results of smear examination of all pulmonary TB cases.

There were constraints of our study. First, results of bacteriological examinations were not available in the NHI reimbursement database. We were not able to determine whether under-notification was associated with bacteriological results. Second, prescription of 2 or more anti-TB drugs was used to identify TB cases. We may miss $\mathrm{TB}$ cases who were not prescribed with antiTB drugs. Third, the NHI database did not specify history of TB treatment. Therefore, previously treated cases may be miss-classified as new cases. Fourth, TB cases who did not participate in the NHI program were not captured by this study. We may under-estimate under notification of these patients. Finally, we did not use capture-recapture technique to estimate completeness of reporting [27]. However, the number of cases included in this study was large and the proportion of population covered by the NHI program was very high, implying that findings of this study is relevant in strengthening surveillance of TB in Taiwan.

\section{Conclusion}

In conclusion, a small proportion of TB cases prescribed with 2 or more anti-TB drugs were not notified and a substantial proportion of notified TB cases had delayed reporting. Under-notification of previously notified TB cases requires immediate attention of the surveillance system as the risk of drug-resistance among retreatment TB cases was substantially higher than that among new TB cases. Taiwan CDC should address factors associated with under-notification and delayed reporting to strengthen surveillance of TB in Taiwan. Countries where the completeness and timeliness of TB notification has not yet been evaluated should take similar action to strengthen surveillance of TB.

\section{Acknowledgements}

This study was officially approved by the Taiwan CDC. The authors would like to thank Office of Statistics of Department of Health and Bureau of
National Health Insurance who provided database for data matching. The authors thank all infection control staff of health care facilities and public health nurses of local public health authorities for their contributions in TB reporting and entering data of TB patients into the National TB Surveillance System of Taiwan CDC.

\section{Author details}

${ }^{1}$ Institute of Public Health, Community Medicine Research Center, National Yang-Ming University, Linong Street, Taipei 11221, Taiwan. ²Department of Health, Centers for Disease Control, Linsen S. Road, Taipei 11050, Taiwan. ${ }^{3}$ Department of Lung Health and NCDs, International Union Against Tuberculosis and Lung Disease, boulevard Saint-Michel, 75006 Paris, France. ${ }^{4}$ Department of Internal Medicine, Wan Fang Hospital, Taipei Medical University, No 111, Section 3 Hsin-Long Road, Taipei 116, Taiwan.

${ }^{5}$ Department of Internal Medicine, School of Medicine College of Medicine, Taipei Medical University, Wu-Hsing Street, Taipei 110, Taiwan.

\section{Authors' contributions}

HYL and CYC proposed and designed the protocol of the study; HYL and SLY performed data analysis and interpreted the results; HYL wrote the first draft of the manuscript; PC and JHC discussed and revised the first draft of manuscript. CYC critically revised and finalized the manuscript. All authors read and approved the final manuscript.

\section{Competing interests}

The authors declare that they have no competing interests.

Received: 27 June 2011 Accepted: 12 December 2011 Published: 12 December 2011

\section{References}

1. Centers for Disease Control, Taiwan: Tuberculosis control report 2010. Centers for Disease Control, Taiwan [http://www.cdc.gov.tw/lp.asp? ctNode $=1947 \&$ CtUnit $=1105 \&$ BaseDSD $=31 \& \mathrm{mp}=1]$, Accessed on 26 January 2011.

2. World Health Organization: TB impact measurement. Policy and recommendations for how to assess the epidemiological burden of TB and the impact of TB control. Stop TB policy paper; no. 2. World Health Organization Document 2009, 1-58, WHO/HTM/TB/2009.416.

3. Chiang $C-Y$, Enarson DA, Yang SL, Suo J, Lin TP: The impact of national health insurance on the notification of tuberculosis in Taiwan. Int $J$ Tuberc Lung Dis 2002, 6:974-979.

4. Bureau of National Health Insurance, Taiwan: National Health Insurance in Taiwan 2010. Bureau of National Health Insurance, Taiwan [http://www.nhi. gov.tw/English/webdata/webdata.aspx?

menu=11\&menu_id=290\&webdata_id=2974\&WD_ID=290], Accessed on 25 June 2011

5. Cheng TM: Taiwan's new national health insurance program: genesis and experience so far. Health Aff 2003, 22:61-76.

6. Doyle TJ, Glynn MK, Groseclise SL: Completeness of notifiable infectious disease reporting in the United States: an analytical literature review. Am J Epidemiol 2002, 155:866-874.

7. Bloch $A B$, Onorato IM, Ihle WW, Hadler JL, Hayden $C H$, Snider DE: The need for epidemic intelligence. Public Health Rep 1996, 111:26-33.

8. Curtis AB, McCray E, McKenna M, Onorato IM: Completeness and Timeliness of Tuberculosis Case Reporting. A Multistate Study. Am J Prev Med 2001, 20:108-112.

9. Maggini M, Salmaso S, Alegiani SS, Caffari B, Raschetti R: Epidemiological use of drug prescriptions as markers of disease frequency. An Italian experience 1991. J Clin Epidemiol 1991, 44:1299-1307.

10. Yokoe DS, Subramanyan GS, Nardell E, Sharnprapai S, McCray E, Platt R: Supplementing Tuberculosis Surveillance with Automated Data from Health Maintenance Organizations. Emerg Infect Dis 1999, 5:779-787.

11. Murray RJ, Hayden CH, Zahn F: Irregular reporting of tuberculosis cases by laboratories in Nassau County, N.Y. Public Health Rep 1974, 89:385-388.

12. Driver CR, Braden CR, Nieves RL, Navarro AM, Rullan JV, Valway SE, McCray E: Completeness of tuberculosis case reporting, San Juan and Caguas regions, Puerto Rico, 1992. Public Health Rep 1996, 111:157-161.

13. Trepka MJ, Beyer TO, Proctor ME, Davis JP: An evaluation of the completeness of tuberculosis case reporting using hospital billing and laboratory data; Wisconsin, 1995. Ann Epidemiol 1999, 9:419-423. 
14. Pillaye J, Clarke A: An evaluation of completeness of tuberculosis notification in the United Kingdom. BMC Public Health 2003, 3:31.

15. Teo SS, Alfaham M, Evans MR, Watson JM, Riordan A, Sonnenberg P, Clark J, Hayward A, Sharland M, Moore-Gillon J, Novelli V, Quinn D, Shingadia D: An evaluation of the completeness of reporting of childhood tuberculosis. Eur Respir J 2009, 34:176-179.

16. Backer HD, Bissell SR, Vugia DJ: Disease reporting from an automated laboratory-based reporting system to the state health department via local county health department. Public Health Rep 2001, 116:257-265.

17. Chiang C-Y, Trébucq A, Billo N, Khortwong P, Elmoghazy E, Begum V, Aditama TY, Ansari A, Baral SC, Vianzon RG: A survey of TB services in hospitals in seven large cities in Asia and North Africa. Int I Tuberc Lung Dis 2007, 11:739-746.

18. Masjedi MR, Fadaizadeh L, Taghizadeh Asl R: Notification of patients with tuberculosis detected in the private sector, Tehran, Iran. Int J Tuberc Lung Dis 2007, 11:882-886.

19. Quy HT, Lan NT, Lönnroth K, Buu TN, Dieu TT, Hai LT: Public-private mix for improved TB control in Ho Chi Minh City, Vietnam: an assessment of its impact on case detection. Int I Tuberc Lung Dis 2003, 7:464-471.

20. Dewan PK, Lal SS, Lonnroth K, Wares F, Uplekar M, Sahu S, Granich R, Chauhan LS: Improving tuberculosis control through public-private collaboration in India: literature review. BMJ 2006, 332:574-577.

21. Irawati SR, Basri C, Arias MS, Prihatini S, Rintiswati N, Voskens J, Kimerling ME: Hospital DOTS linkage in Indonesia: a model for DOTS expansion into government and private hospitals. Int I Tuberc Lung Dis 2007, 11:33-39.

22. Chakaya J, Uplekar M, Mansoer J, Kutwa A, Karanja G, Ombeka V, Muthama D, Kimuu P, Odhiambo J, Njiru H, Kibuga D, Sitienei J: Publicprivate mix for control of tuberculosis and TB-HIV in Nairobi, Kenya: outcomes, opportunities and obstacles. Int J Tuberc Lung Dis 2008, 12:1274-1278

23. Maung M, Kluge $H$, Aye T, Maung W, Noe P, Zaw M, Jost SP, Uplekar M, Lönnroth K: Private GPs contribute to TB control in Myanmar: evaluation of a PPM initiative in Mandalay Division. Int I Tuberc Lung Dis 2006, 10:982-987.

24. Newell JN, Pande SB, Baral SC, Bam DS, Malla P: Control of tuberculosis in an urban setting in Nepal: public-private partnership. Bull World Health Organ 2004, 82:92-98.

25. Yoo HS, Park O, Park HK, Lee EG, Jeong EK, Lee JK, Cho SI: Timeliness of national notifiable diseases surveillance system in Korea: a crosssectional study. BMC Public Health 2009, 9:93.

26. Ward M, Brandsema P, van Straten E, Bosman A: Electronic reporting improves timeliness and completeness of infectious disease notification, The Netherlands, 2003. Euro Surveill 2005, 10:27-30.

27. Bassili A, Grant AD, El-Mohgazy E, Galal A, Glaziou P, Seita A, Abubakar ! Bierrenbach AL, Crofts JP, van Hest NA: Estimating tuberculosis case detection rate in resource-limited countries: a capture-recapture study in Egypt. Int J Tuberc Lung Dis 2010, 14:727-732.

\section{Pre-publication history}

The pre-publication history for this paper can be accessed here: http://www.biomedcentral.com/1471-2458/11/915/prepub

\section{doi:10.1186/1471-2458-11-915}

Cite this article as: Lo et al:: Completeness and timeliness of tuberculosis notification in Taiwan. BMC Public Health 2011 11:915.

\section{Submit your next manuscript to BioMed Central and take full advantage of:}

- Convenient online submission

- Thorough peer review

- No space constraints or color figure charges

- Immediate publication on acceptance

- Inclusion in PubMed, CAS, Scopus and Google Scholar

- Research which is freely available for redistribution

Submit your manuscript at www.biomedcentral.com/submit
Biomed Central 